\title{
Research Paper: \\ Treatment of 44 Cases With Lumbar Spine Stenosis and crossmart Degenerative Instability: Outcomes of Surgical Intervention
}

\author{
Majid Reza Farrokhi ${ }^{1,2 *}$, Golnaz Yadollahikhales ${ }^{1,3}$, Mehrnaz Gholami ${ }^{1}$
}

1. Shiraz Neuroscience Research Center, Shiraz University of Medical Sciences, Shiraz, Iran

2. Department of Neurosurgery, School of Medicine, Shiraz University of Medical Sciences, Shiraz, Iran

3. Department of Neurology, University of Illinois at Chicago, Chicago, Illinois, USA.

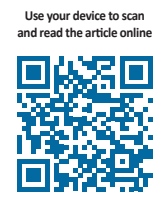

Citation: Farrokhi MR, Yadollahikhales G, Gholami M. Treatment of 44 Cases With Lumbar Spine Stenosis and Degenerative Instability: Outcomes of Surgical Intervention. Iran J Neurosurg. 2017; 3(3):79-88. https://doi.org/10.29252/IRJNS.3.3.79

: https://doi.org/10.29252/IRJNS.3.3.79

Article info:

Received: 15 June 2017

Last Revised: 17 July 2017

Accepted: 3 September 2017
Keywords:

Lumbar spine stenosis, Degenerative instability, Posterior lumbar fusion, Visual Analogue Scale, Oswestry Disability Index

\begin{abstract}
Background and Aim: Degenerative lumbar spine disease can lead to lumbar spine instability. The patients can present with Low Back Pain (LBP), radicular pain, and motor and sensory dysfunction. Age $>50$, female sex and pregnancies are among prevalent risk factors. The degeneration process usually starts from the intervertebral discs progressing to involve facet joints, ligaments, and vertebral bodies leading to spinal instability and deformity. This study aims to evaluate the effect of lumbar decompression and Posterolateral Fusion (PLF) on the short- and long-term outcomes of these patients.
\end{abstract}

Methods and Materials/Patients: This prospective study assessed the effect of lumbar decompression and PLF in patients with lumbar instability referred to the Neurosurgery Clinic of Chamran hospital between March 2011 and March 2013. Forty-four patients with degenerative lumbar spine instability and stenosis were eligible for participation to undergo lumbar decompression and PLF. Its clinical effect was evaluated using Visual Analogue Scale (VAS) score and Oswestry Disability Index (ODI). The change in sagittal and coronal planes was also assessed according to pre- and post-operative findings at 2-year follow-up. The statistical method of assessment was repeated using paired $\mathrm{t}$-test. $\mathrm{P}<0.05$ was considered statistically significant.

Results: The mean preoperative VAS score decreased significantly at 2 years after the surgery $(6.87 \pm 1.07$ vs. $2.20 \pm 1.15 ; P<0.001)$. The comparison between preoperative $O D I$ and its 6 -month, 1 and 2 -year counterparts showed a significant improvement $(P<0.001)$. Moreover, $82.7 \%$ of the patients showed a good fusion rate. The sagittal and coronal angles were reduced significantly after the surgery $(P<0.05)$. Short vs. long segment fusion and inclusion of sacral body did not significantly affect the VAS, ODI scores and the deformity angles.

Conclusion: Lumbar decompression and PLF is a safe and effective method for patients suffering from degenerative lumbar instability.

\section{* Corresponding Author:




\section{Introduction}

umbar instability is defined as an abnormal response to applied loads and is characterized by movement of spinal segments beyond the normal [1, 2]. Due to its weight-bearing properties, lumbar spine is more susceptible to degenerative process in advanced age. The degenerative process normally starts from the intervertebral discs leading to pathologic changes in the ligaments, vertebral bodies and posterior bulging of posterior disk surface, narrowing of the central spinal canal, osteophyte development and sliding of vertebral bodies [3-8].

The degeneration process leads to the sequential phases of reversible dysfunction, instability characterized by a mild disk height reduction, ligament and joint capsule laxity, and facet joint degeneration and the stabilization phase with reduction in spine range of motion [9]. The unstable phase warrants the use of decompression laminectomy with spinal fusion. Although the majority of patients can be symptom free
[10], they may present with mechanical Low Back Pain (LBP), signs of nerve root compression associated by weakness, numbness and tingling, or with cauda equine syndrome [11]. As in other degenerative disorders of the spine, potential risk factors include increasing age $>50$, female sex, number of pregnancies, African-American ethnicity, generalized joint laxity, and anatomical predisposition [12]. Posterior decompression with posterolateral fusion (PLF) is a widely held approach to the surgical management of lumbar instability $[13,14]$. There were a number of studies assessing the effects of posterior decompression and PLF on different lumbar degenerative disease. However, there is still controversy regarding the clinical outcome of those undergoing both decompression and fusion and the use of instrumented fusion.

The Spine Patient Outcomes Research Trial (SPORT) study showed that the patients with degenerative spondylolisthesis who received standard posterior decompressive laminectomy with or without bilateral single-level fusion had better score in SF-36 analysis of bodily pain and physical function in addition to Os-

Table 1. The inclusion and exclusion criteria for patients' selection in this study

$\begin{array}{ll}\text { Patients Selection Criteria } & \end{array}$

4. Patients needed surgical intervention (such as those with progressive neurologic deficits, bladder dysfunction, etc.)

5. Mechanical LBP and neurogenic claudication not responsive to the conservative management for at least 6 months

1. Patients with mental disorders (such as dementia and psychiatric disorders)

2. Previous spine surgeries

Exclusion criteria

3. Patients with lumbar instability having congenital, traumatic or other etiologies

4. Patients who failed to have routine follow-up

5. Sagittal imbalance

6. Patients with infection at the site of surgery 
westry Disability Index (ODI) than those treated nonsurgically [15]. The results of a 10-year follow-up of 130 patients with degenerative lumbar spinal diseases treated with PLF, showed a satisfactory postoperative recovery in $66.9 \%$ of patients and the union rate of $86.5 \%$ [16]. In a study by Chen et al. [17] on 49 patients with grade I to II degenerative spondylolisthesis, it was found that the group for whom internal fixation in decompression and PLF was used had better outcomes with regard to their LBP, spine active function and neurologic function. In Liao et al. [18] study, the ODI has improved significantly in patients with degenerative lumbar diseases treated with posterior decompression, instrumentation, and PLF. In a study using spinal instrumentation without fusion for spinal degenerative diseases, the results were indicative of an improvement in the ODI score and a decrease in LBP and leg pain [19]. The aim of this study was to assess the clinical and radiological results of patients with degenerative lumbar instability treated by posterior decompression, PLF and instrumentation.

\section{Methods \& Materials/Patients}

\section{Patients' evaluation}

We studied 44 patients who had degenerative lumbar spine instability with lumbar spine stenosis referred to the Neurosurgery Clinic of Chamran Hospital, affiliated to Shiraz University of Medical Sciences from March 2011 to March 2013. Table 1 shows the inclusion and exclusion criteria. The Medical Research Ethics Committee as well as Institutional Review Board of Shiraz University of Medical Sciences approved the study protocol before data collection began (approval number: 91-01-01-4438). All patients gave informed consent to participate in this research, and procedures conformed to the declaration of Helsinki.

\section{Inclusion criteria}

The inclusion criteria were 1 ) age $\geq 50,2$ ) Cobb angle $\left.\leq 10^{\circ}, 3\right)$ spinal stenosis with the canal diameter of $\leq$ $10 \mathrm{~mm}, 4)$ patients who needed surgical intervention (such as those with progressive neurologic deficits, bladder dysfunction, etc.), 5) mechanical LBP and neurogenic claudication not responsive to the conservative management for at least 6 months.

\section{Exclusion criteria}

The exclusion criteria were 1) having mental disorders (such as dementia and psychiatric disorders), 2) previous spine surgeries, 3) lumbar instability having congenital, traumatic or other etiologies, 4) not having routine follow-up, 5) sagittal imbalance, and 6) having infection at the site of surgery.

\section{Demographic evaluation}

The patients' pre-operative ODI, radicular pain related VAS score, the 2-year fusion rate and their demographic characteristics including sex, age, body mass index (BMI), occupation, coexisting disease (Diabetes Mellitus (DM)), hypertension (HTN)), and history of trauma and medications were measured. Patients' systemic conditions such as cardiovascular disease, type $2 \mathrm{DM}$, and osteoporosis in addition to their age were considered to decide on how we could approach.

\section{Radiological evaluation}

For all cases, the diagnosis and degree of instability were made based on the magnetic resonance imaging (MRI), computed tomography (CT) scan and static or dynamic radiographs (flexion-extension) combined with the preoperative neurological assessment. Moreover, the patients' imaging findings in X-ray (anteriorposterior, lateral, oblique, flexion-extension), MRI and CT-scan were also recorded.

\section{Outcome measurements}

Patients were followed at 1, 3, 6 months, and 1 and 2 years after surgery. At each follow-up visit, a complete neurological examination was performed. The degree of sagittal and coronal angle correction was also measured [20-23]. The patients' LBP was assessed using Occupational Low Back Pain (OLBP) scale at each follow-up. Follow-up X-ray was taken if indicated based on the neurological examination. The OLBP questionnaire composed of 10 sections including pain intensity, personal care, lifting, walking, sitting, standing, sleeping, sex life, social life, and traveling; each having 6 questions with the total score of 60 . The total ODI score was the percent of patient's OLBP score of the total score in which $0-20 \%$ suggests mild pain, $20-40 \%$ moderate pain, $40-60 \%$ severe pain, $60-80 \%$ crippled and $80-100 \%$ bed bound [24]. The reliability and validity of the OLBP scale questionnaire were previously evaluated in Persian language [25].

The patient's perceived degree of pain was evaluated using VAS scale which is a continuous 10-centimeter long scale commonly anchored by two denominators "no pain" (score of 0 ) and "worst imaginable 


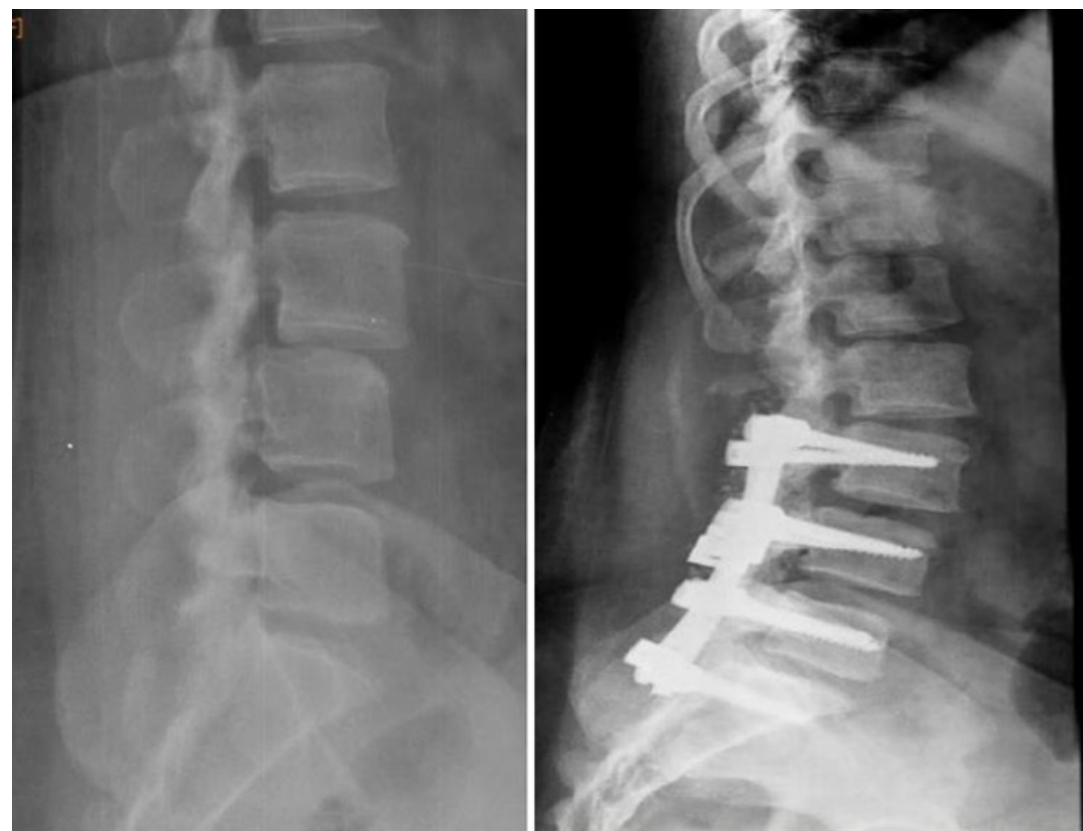

Figure 1. Sagittal plane deformity; pre-operation (Left) and post-operation (right)

pain" (score 10) [26]. The patient was asked to place a mark on the line where it represented their pain intensity. Furthermore, the possible complications of surgery including nerve root injury, dural tears, and superficial infection have also been evaluated at each follow-up visit. Fusion $\leq 3$ levels was regarded as short segment fusion and fusion $\geq 4$ levels was regarded as long segment fusion. Fusion rate was qualitatively measured by $\mathrm{X}$-ray and CT scans after 2 years. Fusion was classified as bony fusion (good fusion), segmental bony fusion (fair fusion), and lack of bony fusion or subluxation in dynamic post-operative radiographies (bad fusion). Successful fusion was defined as the integrated fusion at the fusion bed without motion in a dynamic graph [27-29].

\section{Surgical procedure}

All the patients underwent partial decompressive laminectomy, PLF and spinal fixation with pedicular screws and rods (Implants International Ltd., Teesside industrial estate, Thornby, United Kingdom) [30, 31].
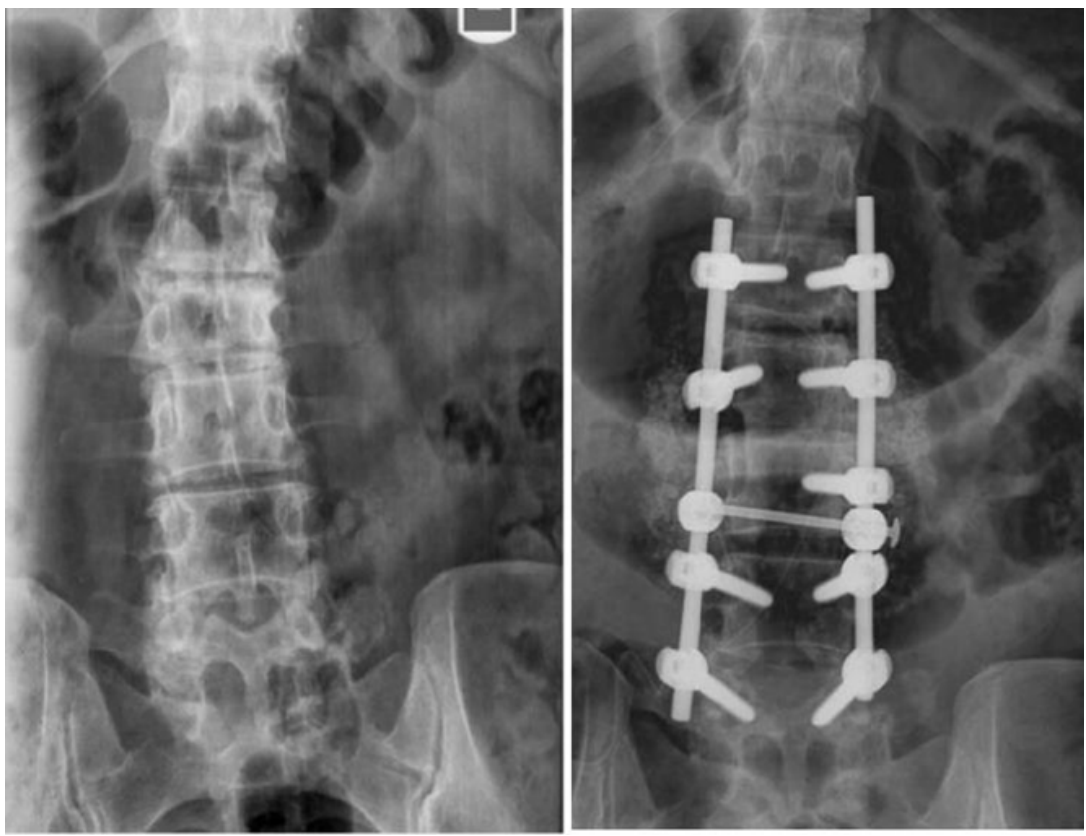

Figure 2. Coronal plane deformity; pre-operation (Left) and post-operation (right) 
Table 2. Demographic variables

\begin{tabular}{|c|c|c|}
\hline Variables & & Number (\%) \\
\hline \multirow{2}{*}{ Sex } & Male & $9(20.4)$ \\
\hline & Female & $35(79.5)$ \\
\hline \multirow{3}{*}{ Occupation } & Housekeeper & $34(77.2)$ \\
\hline & Businessman & $7(15.9)$ \\
\hline & Government employee & $3(6.8)$ \\
\hline \multirow{5}{*}{ ODI (Preoperation) } & Mild & 0 \\
\hline & Moderate & $4(9)$ \\
\hline & Severe & $12(27.2)$ \\
\hline & Crippled & $28(63.6)$ \\
\hline & Bed bound & 0 \\
\hline \multirow{5}{*}{ ODI (3 months after surgery) } & Mild & 0 \\
\hline & Moderate & $18(40)$ \\
\hline & Severe & $22(50)$ \\
\hline & Crippled & $6(13.6)$ \\
\hline & Bed bound & 0 \\
\hline \multirow{5}{*}{ ODI (6 months after surgery) } & Mild & $9(20.4)$ \\
\hline & Moderate & $25(56.8)$ \\
\hline & Severe & $8(18.1)$ \\
\hline & Crippled & $4(9)$ \\
\hline & Bed bound & 0 \\
\hline \multirow{5}{*}{ ODI (1 year after surgery) } & Mild & $18(40.9)$ \\
\hline & Moderate & $20(45.4)$ \\
\hline & Severe & $5(11.3)$ \\
\hline & Crippled & $1(2.2)$ \\
\hline & Bed bound & 0 \\
\hline \multirow{5}{*}{ ODI (2 years after surgery) } & Mild & $30(68.1)$ \\
\hline & Moderate & $12(27.2)$ \\
\hline & Severe & $2(4.5)$ \\
\hline & Crippled & 0 \\
\hline & Bed bound & 0 \\
\hline
\end{tabular}

PLF was done using bone graft and bone substitute. An anterior-posterior and lateral X-ray were taken at the end of the operation. All the patients were operated by the same surgeon.

\section{Statistical analysis}

All analyses were undertaken using the Statistical Package for the Social Sciences version 15.0 (SPSS, Chicago, IL, USA). The statistical method of assessment was repeated measurement and paired t-test. A level of $\mathrm{P}<0.05$ was considered statistically significant.

\section{Results}

Forty-four patients (mean age 55.76 \pm 8.82 ) 9 male and 35 females have met the inclusion criteria. Of 44 patients admitted, LBP (97.6\%) and radicular pain (93.1\%) were the most prevalent chief complaint. The radicular pain was mostly bilateral $(68.1 \%)$ and L4 $(90 \%)$ and L5 $(96.6 \%)$ were the most common involved nerve roots. Neurologic deficit was seen in $40.9 \%$. Table 2 shows the demographic characteristics of the patients. Their respective BMI was $26.90 \pm 3.46$. Their correlation with the ODI at 3 and 6 month was not significant. Degenerative findings in imaging have been listed in Table 3. The 
Table 3. Degenerative parameters in imaging studies (X-ray, CT-scan, MRI)

\begin{tabular}{|c|c|c|}
\hline \multicolumn{2}{|c|}{ Variables } & \multirow{2}{*}{$\begin{array}{c}\text { Number (\%) } \\
36(81.8)\end{array}$} \\
\hline Osteophyte formation & & \\
\hline Sacralization and lumbarization & & $1(2.2)$ \\
\hline Disc degeneration & & 40(90.9) \\
\hline Disc herniation & & $25(56.8)$ \\
\hline \multirow{6}{*}{ Neural foramina narrowing } & $\mathrm{L} 1-2$ & 0 \\
\hline & $\mathrm{L} 2-3$ & 0 \\
\hline & L3-4 & $2(4.5)$ \\
\hline & L4-5 & $11(25)$ \\
\hline & L5-S1 & $5(11.3)$ \\
\hline & Multiple nerve roots & $23(52.2)$ \\
\hline \multirow{6}{*}{ Canal stenosis } & $\mathrm{L} 1-2$ & 0 \\
\hline & $\mathrm{L} 2-3$ & 0 \\
\hline & L3-4 & $1(2.2)$ \\
\hline & L4-5 & $6(13.6)$ \\
\hline & L5-S1 & $3(6.8)$ \\
\hline & Multiple levels & $24(54.5)$ \\
\hline Disc height reduction & & $41(93.1)$ \\
\hline \multirow{6}{*}{ Facet hypertrophy } & $\mathrm{L} 1-2$ & 0 \\
\hline & $\mathrm{L} 2-3$ & $2(4.5)$ \\
\hline & L3-4 & $9(2.0)$ \\
\hline & L4-5 & $17(38.6)$ \\
\hline & L5-S1 & 0 \\
\hline & Multiple levels & $21(47.7)$ \\
\hline Pars fracture & & $12(27.2)$ \\
\hline
\end{tabular}

convexity of curve was to right in $21(47.7 \%)$ and to the left side in 23 patients (52.2\%).

The Comparison between mean preoperative ODI (61.06 $\pm 12.28 \%)$ and its 3- (43.36 $\pm 13.01 \%)$ and 6-months (34.45 $\pm 15.68 \%), 1$-year $(26.88 \pm 12.95)$ and 2-year (18.31 \pm 8.94$)$ follow-ups showed a significant improvement $(\mathrm{P}<0.001)$. The mean preoperative VAS score and the VAS score at 6-month, 1-year and 2-year postoperation were $6.87 \pm 1.07,4.02 \pm 1.49,3.27 \pm 1.21$ and

Table 4. Changes in lumbar plane angle

\begin{tabular}{ccc}
\hline & Sagittal Plane Angle & $7.11 \pm 2.47$ \\
\hline Preoperative & & $5.17 \pm 2.06$ \\
Postoperative & $4.23 \pm 2.14$ \\
At 2 years & Coronal Plane Angle & $5.70 \pm 2.55$ \\
Preoperative & $2.56 \pm 1.77$ \\
Postoperative & $2.14 \pm 1.81$ \\
\hline
\end{tabular}


Table 5. Frequency of the patients with good, fair and bad fusion after 2 years

\begin{tabular}{ccc}
\hline Fair+Bad & Good \\
\hline $27.3 \%$ & $72.7 \%$ \\
\hline [NS
\end{tabular}

$2.20 \pm 1.15$, respectively. The comparison between the preoperative VAS score and its value at 6-month, 1-year and 2-year follow-ups showed a statistically significant reduction $(\mathrm{P}<0.001)$. Moreover, comparison of ODI and VAS scores in patients discovered to have good fusion with those having bad or fair fusion outcome showed a better ODI (15.73 \pm 7.94 vs. $21.24 \pm 4.67, \mathrm{P}<0.05)$ and VAS score $(1.03 \pm 1.12$ vs. $2.05 \pm 1.06, \mathrm{P}<0.05)$ in the former group at 2 years.

One patient (2.2\%) had pure sagittal deformity (L4$5)$ while $27(61.3 \%)$ patients had only coronal plane deformity. There were 16 (36.3\%) patients who had both coronal and sagittal plane deformity. Among those with sagittal plane deformity (Figure 1), 1 patient $(100 \%)$ had both long segment fixation and sacral vertebra included. In patients with coronal plane deformity (Figure 2), 14 (51.8\%) have undergone short, and 17 (48.1\%) long segment fixation. Twenty patients (74\%) had sacral vertebra included. In 16 patients having instability in coronal and sagittal plane, short segment and long segment fusion were orderly done in $13(81.2 \%)$ and $3(18.7 \%)$ patients. 6 patients $(37.5 \%)$ had sacrum fused. By defining short segment fusion as inclusion of one vertebra above and one vertebra below the involved vertebra, there was no difference between the long term outcomes of patients having undergone long segment vs. short segment fusion according to VAS and ODI scores at 2 years $(P=0.58$ and $P=0.61)$. There was also no significant difference in the correction of lumbar deformity in both sagittal and coronal planes according to short vs. long segment fusion $(P=0.28$ and $P=0.34)$. The clinical outcome was also the same comparing those having their sacral vertebra included and those who have not $(P=0.48$ and $P=0.55)$.

Regarding the fusion of sacral bone, no effect was seen on deformity correction in both sagittal and coronal planes at 2-year follow-up ( $P=0.35$ and $P=0.67)$. The comparison between pre, post-operative and 2-year sagittal and coronal plane angle correction revealed a significant decrease in the angle $(P<0.05)$ (Table 4). Table 5 shows the frequency of the patients with good, fair and bad fusion after 2-year post-operation.

\section{Discussion}

In this study, we demonstrated that instrumented PLF with laminectomy improved clinical outcomes and lumbar deformity. 1) The ODI and VAS scores after operation decreased significantly compared with pre-operative ODI. 2) A significant reduction was seen in lumbar the deformity angle after operation. 3) Short or long segment fixation and inclusion of sacral vertebra did not affect the radiological and clinical outcome.

Due to the increased risk of progression of spondylolisthesis after decompression, spinal fusion is recommended as an adjunct to the laminectomy to reduce the risk of the spondylolisthesis progression after decompression [22]. In a study by Herkowitz et al. in 1991. [32] on patients with degenerative spondylolisthesis and spinal canal stenosis, they have found that PLF and laminectomy had better effects on the relief of patients' LBP (1.3 point) and radicular pain (1 point) after a mean follow-up of 3 years compared with laminectomy alone. Furthermore, patients with degenerative spondylolisthesis and spinal canal stenosis showed good to excellent 2-year clinical outcome (76\%) after uninstrumented PLF in Fischgrund et al. in 1997 [33] study. This suggests that spinal fusion is a key factor in patients' short term prognosis. Moreover, the application of decompression alone without fusion may increase the angle of deformity, and segmental instability causing worsening of patients' symptoms. Although decompression is the only required technique in the management of patients with canal stenosis, the existence of lumbar instability in our patients necessitates the use of fusion in order to increase the chance of lumbar plane alignment.

In the long term, instrumented fusion yield satisfactory results with regard to better fusion rate [34]. Furthermore, comparing different instrumentation methods, rigid pedicle screw/rod fixation led to a significantly higher percentage of fusions in degenerative lumbar disease than did fusion without instrumentation or fusion with semi-rigid plate/screw fixation in patients with degenerative spondylolisthesis. Ghogawala, et al. in 2004 [35] have also found that instrumented PLF in patients with lumbar stenosis and degenerative Grade I spondylolisthesis can improve one year ODI score ( 27.5 points 
vs.13.6 points) when compared with decompression. Madan et al. in 2002 [36] found that the ODI score had dropped to less than $30 \%$ after 2 years in 54 of their 74 patients who underwent PLF for spondylolytic spondylolisthesis. Glassman et al. in 2008 [37] found that the preoperative mean ODI score of 55.9 in 119 patients who underwent PLF has improved 23.1 points after 1 year. After 2 years, this had an improvement of 25.1 points.

Fusion status is a critical factor influencing the longterm operative results. In a study by Tsutsumimoto et al. [24] following 42 patients who underwent PLF for degenerative lumbar spondylolisthesis, 31 patients (73.8\%) had demonstrated union defined as less than 2oof angular motion and no translation between the vertebrae at the level of PLF on lateral flexion-extension radiographs causing bilateral continuity in the fusion mass. In another study assessing the effects of instrumented PLF on patients with different lumbar spine degenerative disorders, PLF caused $89.6 \%$ fusion rate [38]. In this study, it has been demonstrated that PLF would result in $72.7 \%$ good fusion rate. The difference in results could be due to the definition of fusion and the degree of degenerative spinal disorders.

There is a controversy regarding the application of short and long segment fixation in patients with degenerative lumbar disorders. In a study comparing the effect of short segment vs. long segment fusion in degenerative coronal plane deformity, it has been shown that long segment fusion corrected the coronal imbalance ( $72 \%$ vs.39\%) and lateral instability more than short segment fusion. However, there was no difference in their ODI score. Some researchers suggest that short segment fusion should be used for patients with lesser Cobb angle or minimal lateral listhesis. Moreover, there is a chance of adjacent segment disease in groups with short segment fixation [39]. In our study, although short segment fixation was the dominant method, there was no difference in clinical and radiological outcome of patients when compared with those undergoing long segment fusions. This may be attributed to the difference in the patients' symptoms and the involved spinal segments causing the preferred use of short or long segment fusion.

There were a few intra and post-operative complications. The intra-operative complications were three unintended duratomy which were managed surgically. Surgical site infection (1 case), persisting foot paresthesia in 2 known cases of DM and mild ankle weakness in dorsiflexion were the post-operative complications. There was only one case whose preexisting urinary urgency did not respond to surgery. The gynecologic consultation was done for her leading to surgical intervention due to uterine prolapse. At 2 years, loosening of screws developed in three patients in the long fusion group. Our total complication rate $(15.9 \%)$ was not more than what has been previously reported. Of 105 patients, Jutte and Castelein in 2002 [40] found 54\% with complications of different degrees of severity, of which $4.7 \%$ had deep infections. Of 132 patients with PLF with instrumentation, Wenger et al. in 2005 [41] found infections in $2.3 \%$ of the patients. The numbers of patients in this study were limited. So, more studies can be done to evaluate the effectiveness and safety of this technique in large scale.

The relatively small sample size was the study limitation. This study sheds new light on the subject and suggests that more detailed prospective future studies with larger samples and longer follow up period should be designed to further investigate the clinical and radiological results of patients with degenerative lumbar instability treated by posterior decompression, PLF and instrumentation. In addition, this study lacks a control group due to the treatment used for the patients which limits the strength of the study's conclusions.

\section{Limitations}

The relatively small sample size was the study limitation. This study sheds new light on the subject and suggests that more detailed prospective future studies with larger samples and longer follow-up period should be designed to further investigate the clinical and radiological results of patients with degenerative lumbar instability treated by posterior decompression, PLF and instrumentation and to compare the results of PLF technique with other interbody fusion techniques such as posterior lumbar interbody fusion (PLIF), transforaminal lumbar interbody fusion (TLIF), lateral lumbar interbody fusion (XLIF), and anterior lumbar interbody fusion (ALIF). In addition, this study lacks a control group due to the treatment used for the patients which limits the strength of the study's conclusions.

\section{Conclusion}

To sum up, our study has shown that PLF with spinal fixation is a promising method in treating the patients suffering from degenerative lumbar instability. This can pave the path for future studies with larger sample size comparing the management of degenerative lumbar instability with different surgical methods such as PLF vs. PLIF, TLIF, XLIF, or ALIF. Moreover, the 
difference between the length of fusion on the patient's outcome can be assessed in another study.

\section{Acknowledgments}

This research did not receive any specific grant from funding agencies in the public, commercial, or notfor-profit sectors. It was extracted from the MD thesis written by Golnaz Yadollahikhales and was financially supported by Shiraz University of Medical Sciences (Grant No. 91-01-01-4438). The authors thank Ms. Hosseini at Shiraz Neuroscience Research Center for her kind assistance.

\section{Conflict of Interest}

There is no conflicts of interest to be declared regarding the manuscript. All Authors contributed equally in all the following steps: Conception and design, data collection, drafting the article, critically revising the article, reviewing submitted version of manuscript, and approving the final version of the manuscript.

\section{References}

[1] Pope MH, Panjabi M. Definitions of spinal instability. Spine. 1985; 10(3):255-6. doi: 10.1097/00007632-198504000-00013

[2] Frymoyer J, Selby D. Segmental instability. Spine. 1985; 10(3):280-6. doi: 10.1097/00007632-198504000-00017

[3] Leone A, Guglielmi G, Cassar-Pullicino VN, Bonomo L. Lumbar intervertebral instability: A review. Radiology. 2007; 245(1):62-77. doi: 10.1148/radiol.2451051359

[4] Farrokhi MR, Haghnegahdar A, Rezaee H, Sharifi Rad MR. Spinal sagittal balance and spinopelvic parameters in patients with degenerative lumbar spinal stenosis; A comparative study. Clinical Neurology and Neurosurgery. 2016; 151:13641. doi: 10.1016/j.clineuro.2016.10.020

[5] Farrokhi MR, Ghaffarpasand F, Khani M, Gholami M. An evidence-based stepwise surgical approach to cervical spondylotic myelopathy: A narrative review of the current literature. World Neurosurgery. 2016; 94:97-110. doi: 10.1016/j. wneu.2016.06.109

[6] Farrokhi MR, Gholami M. In reply to the letter to the editor regarding "an evidence-based stepwise surgical approach to cervical spondylotic myelopathy: a narrative review of the current literature". World Neurosurgery. 2017; 98:848-9. doi: 10.1016/j.wneu.2016.11.108

[7] Farrokhi MR, Vasei M, Fareghbal S, Bakhtazad A. Effect of honey on peridural fibrosis formation after laminectomy in rats: a novel experimental study. Evidence-Based Complementary and Alternative Medicine. 2011; 2011:1-6. doi: $10.1155 / 2011 / 504967$
[8] Farrokhi MR, Gholami M. Can cerebral disease cause cognitive disorders? A review of the literature. Chirurgia (Turin). In Press. doi: 10.23736/S0394-9508.18.04766-6

[9] Kirkaldy-Willis W, Farfan H. Instability of the Lumbar Spine. Clinical Orthopaedics and Related Research. 1982; (165):110-123. doi: 10.1097/00003086-198205000-00015

[10] Fitzgerald J, Newman P. Degenerative spondylolisthesis. The Journal of Bone and Joint Surgery British volume. 1976; 58-B(2):184-92. doi: 10.1302/0301-620x.58b2.932080

[11] MacNab I. Spondylolisthesis with an intact neural archthe so-called pseudo-spondylolisthesis. Journal of Bone \& Joint Surgery, British Volume. 1950; 32(3):325-33. doi 10.1302/0301-620x.32b3.325

[12] Kalichman L, Hunter DJ. Diagnosis and conservative management of degenerative lumbar spondylolisthesis. European Spine Journal. 2007; 17(3):327-35. doi: 10.1007/s00586-0070543-3

[13] Herkowitz HN, Sidhu KS. Lumbar Spine Fusion in the Treatment of Degenerative Conditions: Current Indications and Recommendations. Journal of the American Academy of Orthopaedic Surgeons. 1995; 3(3):123-35. doi: 10.5435/00124635-199505000-00002

[14] Carreon LY, Glassman SD, Howard J. Fusion and nonsurgical treatment for symptomatic lumbar degenerative disease: a systematic review of Oswestry Disability Index and MOS Short Form-36 outcomes. Spine Journal. 2008; 8(5):74755. doi: 10.1016/j.spinee.2007.06.013

[15] Weinstein JN, Lurie JD, Tosteson TD, Hanscom B, Tosteson ANA, Blood EA, et al. Surgical versus Nonsurgical Treatment for Lumbar Degenerative Spondylolisthesis. New England Journal of Medicine. New England Journal of Medicine. 2007; 356(22):2257-70. doi: 10.1056/nejmoa070302

[16] Kuroki H, Tajima N, Kubo S. Clinical results of posterolateral fusion for degenerative lumbar spinal diseases: a followup study of more than 10 years. Journal of Orthopaedic Science. 2002; 7(3):317-24. doi: 10.1007/s007760200054

[17] Chen K, Yang Q, Liu X, Li H. Treatment of degenerative lumbar spondylolisthesis through posterolateral fusion and fixation with pedicle screws. Zhongguo gu shang= China journal of orthopaedics and traumatology. 2010; 23(4):254-6.

[18] Liao JC, Chen WJ, Chen LH, Niu CC. Outcome of the L5S1 segment after posterior instrumented spinal surgery in degenerative lumbar diseases. Chang Gung Medical Journal. 2009; 32(1):81-8. PMID: 19292943

[19] Maleci A, Sambale RD, Schiavone M, Lamp F, Özer F, von Strempel A. Nonfusion stabilization of the degenerative lumbar spine. Journal of Neurosurgery: Spine. 2011; 15(2):151-8. doi: 10.3171/2011.3.spine0969

[20] Farrokhi MR, Alibai E, Maghami Z. Randomized controlled trial of percutaneous vertebroplasty versus optimal medical management for the relief of pain and disability in acute osteoporotic vertebral compression fractures. Journal of Neurosurgery: Spine. 2011; 14(5):561-9. doi: 10.3171/2010.12. spine10286

[21] Farrokhi MR, Lotfi M, Masoudi MS, Gholami M. Effects of methylene blue on postoperative low-back pain and functional outcomes after lumbar open discectomy: a triple-blind, 
randomized placebo-controlled trial. Journal of Neurosurgery: Spine. 2016; 24(1):7-15. doi: 10.3171/2015.3.spine141172

[22] Farrokhi M, Nouraei H, Kiani A. The efficacy of percutaneous vertebroplasty in pain relief in patients with pathological vertebral fractures due to metastatic spinal tumors. Iranian Red Crescent Medical Journal. 2012; 14(9):523-30. PMCID: PMC3482324

[23] Farrokhi MR, Yazdanpanah H, Gholami M, Farrokhi F, Mesbahi AR. Pain and functional improvement effects of methylene blue injection on the soft tissue around fusion site after traumatic thoracolumbar fixation: A double-blind, randomized placebo-controlled study. Clinical Neurology and Neurosurgery. 2016; 150:6-12. doi: 10.1016/j.clineuro.2016.08.018

[24] Fairbanks JCT, Couper J, Davies JB. Modified Oswestry Low Back Pain Disability Questionnaire. Physiotherapy. 1980; 66:271-3.

[25] Mousavi SJ, Parnianpour M, Mehdian H, Montazeri A, Mobini B. The Oswestry Disability Index, the Roland-Morris Disability Questionnaire, and the Quebec Back Pain Disability Scale: Translation and Validation Studies of the Iranian Versions. Spine. 2006; 31(14):E454-E459. doi: 10.1097/01. brs.0000222141.61424.f7

[26] Hawker GA, Mian S, Kendzerska T, French M. Measures of adult pain: Visual Analog Scale for Pain (VAS Pain), Numeric Rating Scale for Pain (NRS Pain), McGill Pain Questionnaire (MPQ), Short-Form McGill Pain Questionnaire (SF-MPQ), Chronic Pain Grade Scale (CPGS), Short Form-36 Bodily Pain Scale (SF-36 BPS), and Measure of Intermittent and Constant Osteoarthritis Pain (ICOAP). Arthritis Care \& Research. 2011; 63(S11):S240-52. doi: 10.1002/acr.20543

[27] Farrokhi MR, Razmkon A, Maghami Z, Nikoo Z. Inclusion of the fracture level in short segment fixation of thoracolumbar fractures. European Spine Journal. Springer Nature; 2010; 19(10):1651-6. doi: 10.1007/s00586-010-1449-z

[28] Farrokhi MR, Kazemi AP, Eftekharian HR, Akbari K. Efficacy of Prophylactic Low Dose of Tranexamic Acid in Spinal Fixation Surgery. Journal of Neurosurgical Anesthesiology. 2011; 23(4):290-6. doi: 10.1097/ana.0b013e31822914a1

[29] Farrokhi MR, Nikoo Z, Gholami M, Hosseini K. Comparison Between Acrylic Cage and Polyetheretherketone (PEEK) Cage in Single-level Anterior Cervical Discectomy and Fusion. Clinical Spine Surgery. 2017; 30(1):38-46. doi: 10.1097/ bsd.0000000000000251

[30] Farrokhi MR, Rahmanian A, Masoudi MS. Posterolateral versus Posterior Interbody Fusion in Isthmic Spondylolisthesis. Journal of Neurotrauma. 2012; 29(8):1567-73. doi: 10.1089/neu.2011.2167

[31] Farrokhi MR, Jamali M, Gholami M, Farrokhi F, Hosseini K. Clinical and radiological outcomes after decompression and posterior fusion in patients with degenerative scoliosis British Journal of Neurosurgery. 2017; 31(5):514-525. doi: 10.1080/02688697.2017.1317717

[32] Herkowitz HN, Kurz LT. Degenerative lumbar spondylolisthesis with spinal stenosis. A prospective study comparing decompression with decompression and intertransverse process arthrodesis. The Journal of Bone \& Joint Surgery 1991; 73(6):802-8. doi: 10.2106/00004623-199173060-00002
[33] Fischgrund JS, Mackay M, Herkowitz HN, Brower R Montgomery DM, Kurz LT. 1997 Volvo award winner in clinical studies: degenerative lumbar spondylolisthesis with spinal stenosis: a prospective, randomized study comparing decompressive laminectomy and arthrodesis with and without spinal instrumentation. Spine. 1997; 22(24):2807-12. doi: 10.1097/00007632-199712150-00003

[34] Tsutsumimoto T, Shimogata M, Yoshimura Y, Misawa H. Union versus nonunion after posterolateral lumbar fusion: a comparison of long-term surgical outcomes in patients with degenerative lumbar spondylolisthesis. European Spine Journal. 2008; 17(8):1107-12. doi: 10.1007/s00586-008-0695-9

[35] Ghogawala Z, Benzel EC, Amin-Hanjani S, Barker FG, Harrington JF, Magge SN, et al. Prospective outcomes evaluation after decompression with or without instrumented fusion for lumbar stenosis and degenerative Grade I spondylolisthesis. Journal of Neurosurgery: Spine. 2004; 1(3):267-72. doi: 10.3171/spi.2004.1.3.0267

[36] Madan S, Boeree N. Outcome of posterior lumbar interbody fusion versus posterolateral fusion for spondylolytic spondylolisthesis. Spine. 2002; 27(14):1536-42. doi: 10.1097/00007632-200207150-00011

[37] Glassman S, Gornet MF, Branch C, Polly Jr D, Peloza $\mathrm{J}$, Schwender JD, et al. MOS short form and Oswestry Disability Index outcomes in lumbar fusion: a multicenter experience. Spine Journal. 2006; 6(1):21-6. doi: 10.1016/j. spinee.2005.09.004

[38] Lidar Z, Beaumont A, Lifshutz J, Maiman DJ. Clinical and radiological relationship between posterior lumbar interbody fusion and posterolateral lumbar fusion. Surgical Neurology. 2005; 64(4):303-8. doi: 10.1016/j.surneu.2005.03.025

[39] Cho KJ, Suk SI, Park SR, Kim JH, Kim SS, Lee TJ, et al. Short fusion versus long fusion for degenerative lumbar scoliosis. European Spine Journal. 2008; 17(5):650-6. doi: 10.1007/ s00586-008-0615-z

[40] Jutte P, Castelein R. Complications of pedicle screws in lumbar and lumbosacral fusions in 105 consecutive primary operations. European Spine Journal. 2002; 11(6):594-8. doi: 10.1007/s00586-002-0469-8

[41] Wenger M, Sapio N, Markwalder T-M. Long-term outcome in 132 consecutive patients after posterior internal fixation and fusion for Grade I and II isthmic spondylolisthesis. Journal of Neurosurgery: Spine. 2005; 2(3):289-97. doi: 10.3171/ spi.2005.2.3.0289 